\title{
Value-driven fears of modern information generations
}

\author{
Vlada I. Pishchik ${ }^{1, *}$ \\ ${ }^{1}$ Don State Technical University, 1, Gagarin Square, 344003, Rostov-on-Don, Russia
}

\begin{abstract}
Today, the problem of formation and life of generations is becoming very relevant. Many researchers in different countries note that representatives of the information younger generations have an increased risk of depression, anxiety and fears. In the study, we note the manifestations of modernity: transitivity of society, fluidity, "uncertainty" and etc. In this regard, young people face fluid socialization, a delay in the period of growing up and excessive parental care. There is a tendency of replacement of real contacts of young people with virtual ones, which can increase the level of anxiety. The trends of changing values in Russia in the direction of survival established earlier by Inglehart and Baker (2000) may have different prospects today. Some researchers show a high level of anxiety among young Russians. The situation with COVID-19 may aggravate these manifestations. Illusory correlations, false representations in the beliefs of young people also increase social anxiety. These realities determined the purpose of the study: to determine the value bases of young generations fears of the modern South of Russia. The sample included: schoolchildren (born in 2004-2005) - 150 people, schoolchildren of the 9th grade and 10th grade, information generation (born in 1995-1999) - 210 people, students, young workers, transition generation (born in 1965-1982) - 245 people, working adults of Rostov-on-Don. We used the following techniques: values were measured by S. Schwartz method, to determine fears we used the V. Pishchik method of determining values through actualized fears. The results of the study showed that the values of preservation and self-affirmation are more pronounced in the "Transition" and "Information" generations. The values of transcendence are expressed in all the studied generations with a greater extent in the "New" generation. The loss of culture scares the "Transitional" generation, the loss of oneself scares the "Information" generation, the information overload scares the "New" generation. We defined the value bases of the fears of the young generations of the modern South of Russia.
\end{abstract}

\section{Introduction}

Generation theory has been widely used in many studies [1-5]. Recent works raise questions about the reality of generational groups, cultural identity, their boundaries, and the formative years $[3,6]$. It is noted that today's younger generations are more exposed to anxiety and depression $[2,7,8,9,10]$. Volková and Dušková (2015) [11] also showed that

\footnotetext{
* Corresponding author: vladaph@yandex.ru
} 
certain age groups exhibit their own specific fears [12]. For us, it remains unclear how strong this trend is in Russia. The focus of our research is the problem of fears and anxieties in connection with the values of groups of young generations in the Southern region of Russia.

When we try to recreate the framework of the modernity of generations life, we turn to the analysis of the following phenomena: "individualization" in society [13], "fluid modernity" [14], "transitive society" [15, 16], "personality in the era of change", "personality dissonance syndrome with time" Asmolov (2016), etc. The present time is characterized by "blurring of boundaries", "flexibility", "fluidity", "uncertainty", "transitivity", etc. [17].

Generations exist in a "transitive society". It is characterized by radical social transformations, when all social institutions in society suffer a crisis. This leads to an increase in the duration of the time period of the process of young people socialization and can stimulate "activation of resocialization" and "fluid socialization" [16]. In his work, Twenge (2017) notes similar trends in the American younger generations, who suffer the process of delaying the stages of adulthood [2]. Those who grow up longer are more anxious in their lives.

Contacts play a major role in reducing anxiety. Globalization has led to the expansion of the space, including the space of interpersonal contacts, in the Internet. This expanded the information space and strengthened its role in the formation of young generations [4, 18]. As Martsinkovskaya (2019) notes, this space partially replaces intergenerational connections [16]. At the same time, it is noted that the number of real contacts is decreasing $[2,19]$. Anxiety is controlled by the information field of the Internet. Avoiding direct contact and replacing it with virtual contact often increases social anxiety [20].

The change in the information and subcultural space of the younger generation, the transformation of the meanings of life, values, standards and norms of behavior are another manifestations of transitive society. In 2000 Inglehart and Baker recorded a change in the main value trends in the world, expressed in the movement from the values of survival to the values of self-expression [21]. But they noted, and other authors confirmed the idea that the inhabitants of Russia remain in the values of survival [22]. This may also be indirect evidence of high anxiety in the population. The question is "How much our younger generation lives in changing meanings and values?"

The birth of new meanings in society causes the emergence of new types of personality. The emergence of a new type of personality - "Zwischens" (a person who makes decisions in situations of uncertainty), is noted by some authors [15]. The new person constructs new ways of communication, lives in a situation of interrupted traditions, uncertainty, export of values. And those who do not fit into the new type are obviously worried.

Such instability actualizes the ideas of the catastrophization of the world. Bauman, Donskis (2019) write that the modern world is characterized by: the lack of alternatives, not trendy optimism, the prevalence of fear, denial, the expectation of bad news, the loss of historical memory and moral amnesia, looking for attention, consumerism, the lack of personal secrets, privacy, values neutrality, not serious relations [14]. The authors conclude that the contemporaries are a crowd of loners.

The current situation with COVID-19 only reinforces these trends [23, 24]. Anxiety and fears have a detrimental effect on the quality of life of generations: they actualize irrational tendencies, narrow the picture of the world, lead to a loss of common sense, take away energy, etc.

The model of social anxiety disorder Clark, Wells (1995) states that three types of nonadaptive social beliefs (high standards, conditional and unconditional beliefs) play a crucial role in the development of fear [25]. Wiemer, Pauli (2016) demonstrated in a study that fearrelated illusory correlations may be involved in the maintenance of anxiety disorders and are best explained by both a priori expectations and biased coding of experienced associations $[26]$. 
Such complex socio-psychological phenomena in society actualize the study of the problem of fears in connection with the changing values of modern young generations.

Generations who are constrained by this situation in society, in the world are: "Traditional, Soviet generation", years of birth 1946-1964, bearers of traditional mentality. "Unbelievers, the transitional generation" years of birth 1965-1983, bearers of transition mentality, "Information generation" years of birth 1984-2002, bearers of innovation mentality, "New, networked generation", bearers of post innovative mentality, years of birth 2003-2021. All of them are affected by the current situation of the society development.

\section{Sample of research}

In our empirical study, the sample was represented by the following groups of generations of the city of Rostov-on-Don: schoolchildren (born in 2004-2005) - 150 people, schoolchildren of the 9th grade and 10th grade of schools and lyceums, information generation (born in 1995-1999) - 210 people, students, young workers, transition generation (born in 1965-1982) - 245 people, working adults. Table 1. Table captions should be placed above the tables.

\section{Methods}

The survey was conducted partly online, partly by distributing and filling out methodology forms. Values were measured by the method of S. H. Schwartz [27]. To determine fears, we used the method of determining values through actualized fears [28]. We used the SPSS software version 22 for data analysis. The Mann-Whitney test (U) for independent samples proved hypotheses about the validity of differences.

We used the Schwartz method, for the study of personal values, since the second method is used for the study of cultural values. The methodology is a structured questionnaire. It contains statements of agreement or disagreement that the respondent must express. The method described was adapted for the Russian respondents. The method presents 10 values that were different in motivational orientation (power, achievement, hedonism, stimulation, independence, universalism, kindness, tradition, conformity, security). In the questionnaire, the subject evaluates the importance of the value from 1 to 7 points. Then the average value is calculated for each value and the significance of the value for the respondent is determined. The very first ranks are occupied by values that are the most important ones for the individual.

The next method was the method for measuring values through fears. According to our research, the emergence of fear is a response to a threat to values that are important to a person. The methodology of value measurement of fears developed by us is based on the study of the significance for the individual of threats to such categories as: "I", "Others", "Nature", "Culture", "Technology", "Mystical". The methodology consists of two parts. In the first one, it is proposed to rank the values according to the degree of significance for the subject (from 0 to 5 points). The second task is to assess whether an individual has actual fears related to each value (from 0 to 5 points). The data processing is carried out by calculating the average values for preferred values and expressed fears.

The research hypotheses are: H1: we assume that the hierarchy of values is different in the generational groups. H2: fears vary across generational groups.

\section{Results}

The results for values are presented in Table 1 . 
Table 1. The values of the generations.

\begin{tabular}{|c|c|c|c|c|c|c|c|c|c|c|c|c|}
\hline \multirow{2}{*}{ Values } & \multicolumn{3}{|c|}{ Min. } & \multicolumn{3}{|c|}{ Max. } & \multicolumn{3}{|c|}{ M } & \multicolumn{3}{|c|}{ SD } \\
\hline & $\mathbf{X}$ & $\mathbf{Y}$ & $\mathbf{Z}$ & $\mathbf{X}$ & $\mathbf{Y}$ & $\mathbf{Z}$ & $\bar{X}$ & $\mathbf{Y}$ & $\mathbf{Z}$ & $\mathbf{X}$ & $\mathbf{Y}$ & $\mathbf{Z}$ \\
\hline \multicolumn{13}{|l|}{ Preservation } \\
\hline Conformity & 7.0 & 4.0 & 4.0 & 37.0 & 36.0 & 24.0 & 17.0 & 16.57 & 14.9 & 5.7 & 5.6 & 5.2 \\
\hline Traditions & 3.0 & 2.0 & 1.0 & 33.0 & 67.0 & 30.0 & 19.1 & 18.1 & 12.9 & 6.5 & 10.5 & 7.5 \\
\hline Safety & 0.0 & 0.0 & 1.0 & 34.0 & 36.0 & 50.0 & 24.8 & 23.4 & 13.8 & 6.8 & 6.3 & 6.3 \\
\hline \multicolumn{13}{|l|}{ Transcendence } \\
\hline Kindness & 13.0 & 9.0 & 1.0 & 114. & 95.0 & 95.0 & 26.9 & 25.4 & 23.9 & 15.8 & 14.9 & 11.6 \\
\hline Universalism & 21.0 & 8.0 & 8.0 & 52.0 & 78.0 & 53.0 & 36.6 & 20.2 & 32.6 & 8.56 & 9.9 & 9.9 \\
\hline \multicolumn{13}{|l|}{$\begin{array}{ll}\begin{array}{l}\text { Openness } \\
\text { changes }\end{array} & \text { to } \\
\end{array}$} \\
\hline Independence & 13.0 & 3.0 & 5.0 & 59.0 & 38.0 & 33.0 & 26.2 & 14.4 & 13.2 & 7.54 & 6.2 & 4.8 \\
\hline Stimulation & 0.0 & 14.0 & 9.0 & 21.0 & 68.0 & 89.0 & 13.4 & 26.3 & 24.7 & 4.3 & 8.5 & 10.0 \\
\hline \multicolumn{13}{|l|}{$\begin{array}{l}\text { Self- } \\
\text { affirmation }\end{array}$} \\
\hline Hedonism & 3.0 & 4.0 & 5.0 & 36.0 & 20.0 & 26.0 & 12.3 & 13.0 & 14.9 & 5.2 & 3.9 & 5.2 \\
\hline Power & 0.0 & 0.0 & 6.0 & 21.0 & 24.0 & 33.0 & 13.1 & 14.4 & 22.5 & 5.4 & 5.7 & 5.3 \\
\hline Achievements & 13.0 & 17.0 & 1.0 & 67.0 & 65.0 & 82.0 & 20.3 & 34.7 & 19.3 & 8.7 & 9.4 & 9.9 \\
\hline
\end{tabular}

Abbreviations: $\mathrm{X}-$ «Transition» generation, $\mathrm{Y}-$ «Information» generation, $\mathrm{Z}-$ «New» generation.

In all three groups, the value "Kindness" was expressed, which indicates, according to Schwartz, the tendency to preserve the well-being of close people. In the group of "New" generation, the value of "Power" is clearly expressed $(\mathrm{U}=501,0, \mathrm{p}=0,003)$, which indicates a desire to dominate people and resources. In the groups of "Information" and "New" generations, the value of "Stimulation" prevails, which indicates the desire for novelty. The "Transitional" and "New" generations prefer the value "Universalism", which is manifested in tolerance, protection of well-being. The "Transition" and "Information" generations strive for security. The "Information" generation tends to achieve more $(U=273,7, p=0,002)$. The "Transition" generation is distinguished by the value "Independence" $(U=403,6, p=0,001)$.

The generational fears are presented in Table 2.

Table 2. Generational fears.

\begin{tabular}{|c|c|c|c|c|c|c|c|}
\hline \multirow{2}{*}{ № } & \multirow{2}{*}{ Scales of techniques } & \multicolumn{6}{|c|}{ Type of generation } \\
\cline { 3 - 9 } & & $\mathbf{M}$ & $\mathbf{X}$ & $\mathbf{3}$ & \multicolumn{3}{|c|}{ Z } \\
\hline I & Value «I» & 4 & 0.5 & $\mathbf{6}$ & 0.5 & 4 & 0.4 \\
\hline 1 & I am afraid to be lost for myself. & 3 & 1.3 & $\mathbf{4 . 5}$ & 2.4 & 5 & 5.7 \\
\hline 2 & $\begin{array}{c}\text { I am afraid that I don't love } \\
\text { anyone. }\end{array}$ & $\mathbf{5 . 1}$ & 2.7 & 2.2 & 2.1 & 3 & 2.3 \\
\hline 3 & $\begin{array}{c}\text { I am scared by the fact that I have } \\
\text { lost sense in many aspects of life }\end{array}$ & $\mathbf{5}$ & 3.6 & 3.1 & 2.1 & $\mathbf{6}$ & 2.6 \\
\hline 4 & $\begin{array}{c}\text { I am scared when I don't feel my } \\
\text { body }\end{array}$ & 1 & 2.5 & 2.65 & 2.2 & 4 & 4.5 \\
\hline 5 & I am afraid to make a choice & 2 & 1.2 & 2.35 & 4.2 & 2 & 5.2 \\
\hline II & Value «Others» & 3 & 0.5 & 3 & 0.5 & 2 & 0.3 \\
\hline 1 & $\begin{array}{c}\text { I am being threatened - it is } \\
\text { dangerous }\end{array}$ & 3 & 2.4 & 2.5 & 3.3 & $\mathbf{6}$ & 4.8 \\
\hline 2 & $\begin{array}{c}\text { It scares me that I have lost a } \\
\text { significant and close person }\end{array}$ & 4 & 3.5 & $\mathbf{3 . 5}$ & 7.2 & 3 & 5.1 \\
\hline 3 & $\begin{array}{c}\text { I am being humiliated and it } \\
\text { worries me }\end{array}$ & 1 & 1.6 & 1.6 & 3.5 & 2 & 2.3 \\
\hline 4 & I have no ideals. isn't it dangerous? & 1 & 2.1 & 2.1 & 2.8 & $\mathbf{5}$ & 4.05 \\
\hline 5 & The most dangerous thing is to lose & $\mathbf{5}$ & 3.3 & 3.3 & 5.2 & 4 & 2.5 \\
\hline
\end{tabular}




\begin{tabular}{|c|c|c|c|c|c|c|c|}
\hline & $\begin{array}{c}\text { good relationships with other } \\
\text { people }\end{array}$ & & & & & & \\
\hline III & Value «Nature» & $\mathbf{5}$ & 0.3 & 4 & 0.5 & 3 & 0.3 \\
\hline 1 & I am afraid of warming climate & 1 & 4.7 & 2.8 & 2.5 & $\mathbf{6}$ & 7.9 \\
\hline 2 & $\begin{array}{c}\text { I am afraid of environment } \\
\text { pollution }\end{array}$ & 3 & 3.1 & 1.9 & 3.7 & 3 & 5.4 \\
\hline 3 & $\begin{array}{c}\text { The most horrible things are } \\
\text { natural disasters }\end{array}$ & $\mathbf{4}$ & 3.5 & $\mathbf{3 . 8}$ & 4.8 & 2 & 3.6 \\
\hline 4 & $\begin{array}{c}\text { I realize that ecological crisis is the } \\
\text { most dangerous thing in the world }\end{array}$ & 2 & 2.8 & 3.4 & 5.9 & 4 & 4.9 \\
\hline 5 & I am afraid of epidemics & $\mathbf{5}$ & 2.1 & $\mathbf{3 . 3}$ & 4.2 & $\mathbf{5}$ & 3.2 \\
\hline IV & Value «Technologies» & 2 & 0.5 & 2 & 0.3 & $\mathbf{6}$ & 0.5 \\
\hline 1 & $\begin{array}{c}\text { I am afraid when I don't have } \\
\text { enough information }\end{array}$ & 3 & 4.7 & $\mathbf{3 . 2}$ & 6.1 & 3 & 4.7 \\
\hline 2 & $\begin{array}{c}\text { I am afraid when there is too much } \\
\text { information }\end{array}$ & $\mathbf{5}$ & 2.4 & 2.6 & 5.9 & $\mathbf{6}$ & 3.8 \\
\hline 3 & $\begin{array}{c}\text { The multiplicity of worlds is a } \\
\text { threat }\end{array}$ & 2 & 1.9 & 1.6 & 4.2 & 2 & 2.7 \\
\hline 4 & Robots are dangerous & 1 & 3.7 & 1.6 & 4.8 & $\mathbf{5}$ & 8.4 \\
\hline 5 & $\begin{array}{c}\text { Technologies are imperfect and } \\
\text { they threaten }\end{array}$ & $\mathbf{4}$ & 4.8 & 2.3 & 3.1 & 4 & 6.3 \\
\hline V & Value «Mythical» & 1 & 0.4 & 1 & 0.4 & 5 & 0.4 \\
\hline 1 & God can punish me & $\mathbf{5}$ & 6.9 & 3 & 4.6 & $\mathbf{6}$ & 4.8 \\
\hline 2 & Dark forces can cause harm & 3 & 3.7 & 2.3 & 7.5 & $\mathbf{5}$ & 5.4 \\
\hline 3 & $\begin{array}{c}\text { I don't differentiate reality and } \\
\text { unreality - it scares me }\end{array}$ & 1 & 4.6 & 1.5 & 6.4 & 4 & 7.8 \\
\hline 4 & Soul is immortal - it's undeniable & 4 & 3.2 & $\mathbf{3 . 5}$ & 5.1 & 3 & 5.5 \\
\hline 5 & $\begin{array}{c}\text { I have a mythical experience in life } \\
\text { it's scary }\end{array}$ & 1 & 4.9 & 2.5 & 2.7 & 2 & 4.9 \\
\hline VI & Value «Culture» & $\mathbf{6}$ & 0.5 & 5 & 0.4 & 1 & 0.3 \\
\hline 1 & $\begin{array}{c}\text { Culture is disappearing - it's not } \\
\text { safe }\end{array}$ & $\mathbf{5}$ & 7.5 & $\mathbf{3 . 9}$ & 5.5 & 4 & 5.8 \\
\hline 2 & It scares me that we lose traditions & 4 & 8.3 & 3 & 4.8 & 5 & 5.9 \\
\hline 3 & $\begin{array}{c}\text { We face innovations - it's not } \\
\text { safe }\end{array}$ & 1 & 4.7 & 1.9 & 5.9 & 4 & 6.8 \\
\hline 5 & $\begin{array}{c}\text { It worries me that there are many } \\
\text { cultures and there are no } \\
\text { boundaries between them }\end{array}$ & 3 & 3.6 & 2.1 & 5.3 & 3 & 4.7 \\
\hline $\begin{array}{c}\text { I am afraid of anti-culture } \\
\text { predominance }\end{array}$ & 2 & 4.8 & $\mathbf{3 . 8}$ & 2.6 & $\mathbf{6}$ & 5.2 \\
\hline
\end{tabular}

The value of "I" in the "Transitional" generation is dominated by fears about the small attachment to others $(\mathrm{U}=573,1, \mathrm{p}=0,000)$ and loss of the senses equally, in the group of "Information" generation dominates the fear of loss of yourself $(\mathrm{U}=761,3, \mathrm{p}=0,002)$, in the group of the "New generation" dominates the fear of loss of meaning.

The value of "Other" in the "Transitional" generation is dominated by fears about the loss of good relations ( $\mathrm{U}=502,0, \mathrm{p}=0,001)$, in the "Information" generation it is dominated by the fear of loss of a significant other, in the group of the "New generation" dominates the fear of threat and loss of ideals $(\mathrm{U}=784,0, \mathrm{p}=0,000)$.

The value of "Nature" in the "Transitional" generation is dominated by fear of epidemics and natural disasters, in the "Information" generation - the fear of natural disasters and epidemics, in the group of the "New generation" - the fear of the threat of climate warming $(\mathrm{U}=362,5, \mathrm{p}=0,000)$ and epidemics.

The value of "Technology" in the groups of "Transition" and "New" generations is dominated by fears of an excess of information. The "New" generation has a fear of robots 
$(\mathrm{U}=521,3, \mathrm{p}=0,000)$. In the group of the "Information" generation, the fear of a lack of information prevails.

The value of the "Mystical" in the group of the "Transitional" generation is dominated by the fear of God's punishment. In the group "Information" generation it is dominated by the fear of inevitability of the immortality of the soul, in the group of the "New generation" dominates the fear of the threat of God's punishment and secret forces.

The value of "Culture" in the "Transitional" generation is dominated by fear of disappearance of culture $(\mathrm{U}=733,2, \mathrm{p}=0,005)$, in the "Information" generation - the fear of the disappearance of the culture, anticulture, in the group of the "New generation" dominates the fear of anticulture $(\mathrm{U}=579,7, \mathrm{p}=0,001)$.

\section{Discussion}

Our research confirms that generations in society have a divergence in leading values, but there are similarities within generational groups. The result is consistent with the research of Morris (2014), who argues that a low social consensus in cultural values, which may indicate that the dominant paradigm-culture as common values-may be a mistake [29].

The "Transition" and "Information" generations strive for security, which is confirmed by the study of Inglehart, Baker (2000) [21]. But this is not inherent in the representatives of the "New" generation, as shown in our study, which diverges with the data of Twenge (2017) [2].

According to Yakovleva (2018), the core values of the younger generations are still dominated by the family, as well as by the older ones. In the second place is self-realization, which is similar to our result, when the values of openness to change prevail among the representatives of the "Information" and "New" generations [30]. And for all generations, our study expressed the value of "Kindness", which is consistent with family values.

Vecchione, Schwartz, Davidov, Cieciuch, Alessandri, Marsicano (2020) observed adolescents. It was found out that the values of independence and hedonism showed the greatest growth [31]. The values of conservation and self-transcending have not changed, with the exception of tradition, which has somewhat diminished. This is not consistent with our research. In our school representatives (the "New" generation), the values of "Universalism", "Kindness" and "Stimulation" were more vivid. We think that the cultural context also plays a role.

We found out that the values of the "Transition" and "Information" generations have contradictory tendencies: conservatism (preservation) and openness to change. There is no such contradiction in the values of the "New" generation, since there are tendencies of openness to change and self-transcendence. Here, most likely, we are faced with intergenerational differences, which are due to the historical context of the formation of generations.

The presented results reveal the value palette of generations. The representatives of "Transitional" generation are dominated by the value of "Culture" and there is a great desire to keep it. This can be explained by the fact that the formation of the generation fell on the years of the beginning of perestroika, when the collapse of the USSR occurred and many were psychologically traumatized, because they were not ready for a new life.

The representatives of the "Information" generation are dominated by the value of "I" and have difficulties in accepting themselves. It is possible that this reflects their individualistic mentality, the predominance of material priorities. This may be a manifestation of narcissism. This generation witnessed numerous terrorist attacks, which influenced the formation of a sense of the fragility of the world and the shortness of life. This is combined with a study by Narbut and Trotsuk (2018), which showed that students agreed that most people today are only concerned with their own problems and are indifferent to the 
problems of others (62\%) [32]. According to students, the main problems of our time are drug addiction, alcoholism and the moral degradation of society.

Among the representatives of the "New" generation, the value of "Technologies" dominates and the emphasis on their uniqueness is revealed. They are not accidentally referred to as "Digital Native" - the indigenous inhabitants of the digital society, they are also called the "Network" generation. Although modern Russian studies of this generation dispute this characterization [19, 33, 34].

Despite the fact that the study [35] shows that $32.31 \%$ of respondents did not answer, did not determine their position, $20.31 \%$ of respondents believe in the best future and look in it with optimism, $12.9 \%$ are not afraid of anything and believe in their own strength, but this is somehow contradicts with our results, we found a lot of fears among representatives of modern generations.

Many studies emphasize that modern Z ("New") generation is optimistic about the future. In the study Volková, Dušková (2015) confirmed the general tendency to reduce the fears of Czech adolescents, observed a decrease in the fear of physical danger and death, while there was an increase in school fears and fear of failure [11]. In our study, they found the following fears: loss of meaning, threats from outside, climate warming, information overload, robots, the fear to God, anti-culture.

The study of Narbut, N. P., Trotsuk (2018) revealed the fears of students: not having time to complete a task in school, achieve family well-being, terrorist threat, crime, get HIV infection [32]. This is combined with the results we have obtained. We have demonstrated that representatives of the "Information" generation are afraid of personal losses, epidemics, natural disasters, and the disappearance of culture. This is comparable to the Yakovleva (2018) study, which shows that the value of confidence in the future decreased from $48.5 \%$ to $28.8 \%$ from 2008 to 2016 [30].

The fears of adult respondents of the "Transition" generation are associated in our study with the loss of meaning in some aspects of life, the loss of feelings, and the destruction of relationships with others $[36,37]$. This is combined with a study by Volková, Dušková (2015), which showed that for adults, partner-related fears and employment-related fears can be typical. In this case, the results were influenced by age and social factors [11].

\section{Conclusion}

The hypotheses put forward in our study were confirmed. Indeed, there are differences in the representation of values and fears in the generational groups.

The special priority of the values of generations indicates significant anxieties and fears in their picture of the world. This concerns the problems of their safety, well-being, and quality of life. The values of preserving and self-affirmation are more prominent in the "Transitional" and "Information" generations, so they have fears related to culture and their own "I". The fear of information overload in the "New" generation is associated with the value of "Technology".

The predominance of fear categories illustrates the cognitive, social, and emotional development of a given generation, but also includes the influence of the external environment and the historical and social context in which respondents find themselves today.

The results of the study can be used in working with students. 


\section{Acknowledgements}

The article was prepared with the financial support of the Russian Foundation for Basic Research. Project No. 18-29-22004 «Psychological and genetic research of the predictors that determine the behavior of users in the perception of Internet content of various informational orientation».

\section{References}

1. Howe N., Strauss W.: Instruction 21, 574-586 (1991) doi:10.1016/j.learninstruc.2010.12.001

2. Twenge, J.M.: iGen: Why today's super-connected kids are growing up less rebellious, more tolerant, less happy- and completely unprepared for adulthood and what that means for the rest of us. New York, NY: Atria Books (2017)

3. Campbell, S.M., Twenge, J.M., Campbell, W.K.: Work, Aging and Retirement 3(2), 130-139 (2017) https://doi.org/10.1093/workar/wax001

4. Miklyaeva, A.V., Postnikova, M.I.: Social Psychology and Society 10(2), 114-126 (2019) doi:10.17759/sps.2019100209

5. Pishchik V.: E3S Web Conf. 210, 20007 https://doi.org/10.1051/e3sconf/202021020007

6. Rudolph, C., Rauvola, R.S., Costanza, D., Zacher, H.: DOI: 10.31234/osf.io/yq64d (2020)

7. Kross, E., Verduyn, P., Demiralp, E., et al., PLoS ONE 8(8), e69841 (2013) https://doi.org/10.1371/journal.pone.0069841

8. Warner, V., Wickramarante, P., Grillon, C., Weissman, M.M.: Comprehensive Psychiatry 54(1), e12-e13 (2013) https://doi.org/10.1016/j.comppsych.2012.07.054

9. Duffy, M.E., Twenge, J.M., Joiner, T.E.: Journal of Adolescent Health 65(5), 590-598 (2019). DOI: 10.1016/j.jadohealth.2019.04.033

10. Lawrence, K.C.: Cogent Psychology 7(1) (2020) DOI: 10.1080/23311908.2020.1835383

11. Volková, A., Dušková, P.: Procedia - Social and Behavioral Sciences 171, 487-493 (2015) https://doi.org/10.1016/j.sbspro.2015.01.151

12. Rudenko, A.M., Rodionova, V.I., Stepanova, V.N.: Advances in Intelligent Systems and Computing, 726. Springer, Cham (2019) https://doi.org/10.1007/978-3-319-908359_129

13. Triandis, H. C.: Encyclopedia of applied psychology (1, 555-560). Cambridge, MA, USA: Academic Press (2004).

14. Bauman, Z., Donskis, L.: Liquid Evil. Cambridge: Polity (2016) https://books.google.ru/books?id=ge4XDAAAQBAJ\&redir_esc $=y$

15. Fedotova, M. G.: Bulletin of Vyatka State University 1(4), 28-31 (2010) URL: http://vestnik43.ru/1(4)-2010.pdf

16. Martsinkovskaya, T.D.: Counseling Psychology and Psychotherapy 27(3), 77-96 (2019) doi:10.17759/cpp.2019270306

17. Asmolov, A.G.: Procedia - Social and Behavioral Sciences 233, 27-34 (2016) https://doi.org/10.1016/j.sbspro.2016.10.122 
18. Zhdanko, A.: International Journal of Cognitive Research in Science, Engineering and Education 7(1), 35-42 (2019) DOI: 10.5937/IJCRSEE1901035Z

19. Soldatova, G.U.: Social Psychology and Society 9(3), 71-80 (2018) doi: $10.17759 /$ sps. 2018090308

20. Kholmogorova, A.B., Avakyan, T.V., Klimenkova, E.N., Malyukova, D.A.: Counseling psychology and psychotherapy 23(4), 102-129 (2015) doi:10.17759/cpp.2015230407

21. Inglehart, R., Baker, W.E.: American Sociological Review 65, 19-51 (2000).

22. Guseltseva, M.S.: Psikhologicheskie Issledovaniya, 11(58), 2 (2018) http://psystudy.ru

23. Rao, H.R., Vemprala, N., Akello, P., Valecha, R.: International Journal of Information ManagementIn, 102187 (2020) https://doi.org/10.1016/j.ijinfomgt.2020.102187

24. Martínez-Lorca, M., Martínez-Lorca, A., Criado-Álvarez, J.J., et al., Psychiatry Research 293 (2020) https://doi.org/10.1016/j.psychres.2020.113350

25. Clark, D.M., Wells, A.: A cognitive model of social phobia. In Social phobia: Diagnosis, assessment, and treatment. New-York: Guilford Press, 69-93 (1995)

26. Wiemer, J., Pauli, P.: Journal of Anxiety Disorders 42, 113-128 (2016) https://doi.org/10.1016/j.janxdis.2016.07.003

27. Schwartz, S.H.: Comparative Sociology 5(2-3), 137-182 (2006) doi:10.1163/156913306778667357

28. Pishchik, V.I.: Social Psychology and Society 10(2), 67-81 (2019) doi:10.17759/sps.2019100206

29. Morris M.W.: Journal of Cross-Cultural Psychology (IACCP) 45(1), 14-24 (2014). https://doi.org/10.1177/0022022113513400

30. Yakovleva, M.N. Dynamics of value orientations of modern youth. In Meanings of the life of the Russian intelligentsia. Moscow: Russian State University for the Humanities 212-219 (2018). https://www.isras.ru/index.php?page_id=1198\&id=6073

31. Vecchione, M., Schwartz, S.H., Davidov, E., et al., Personality 88(3), 447-463 (2020). https://doi.org/10.1016/j.jrp.2016.06.002

32. Narbut, N.P., Trotsuk, I.V.: Bulletin of the Peoples' Friendship University of Russia. Series: Sociology 18(1), 131-155 (2018) DOI: 10.22363/2313-2272-2018-18-1-131-155

33. Nikishina, V., Petrash, E., Morgun, A., Zapesotskaya, I.: Psikhologicheskii zhurnal 41(4), 78-91 (2020). DOI: 10.31857/S020595920009331-0

34. Dautov, D., Korochentseva, A., Al Hussini, M. K. M. SHS Web of Conferences. EDP Sciences 70, 06001 (2019). https://doi.org/10.1051/shsconf/20197006001

35. Sokolovskaya, I.E.: Human capital 3(63), 45-50 (2014). http://elibrary.ru/item.asp?id=22003950

36. Abakumova, I. V., Ermakov, P. N., Kolesina, K. Y.: Psychology in Russia: State of the Art 9(1), 155-163 (2016) https://doi.org/10.11621/pir.2016.0111

37. Suroedova, E., Tushnova, Y., Belousova, E. E3S Web of Conferences, 2020, 175, 15028. https://doi.org/10.1051/e3sconf/202017515028 